\title{
Tensão e Ambiguidade NA Filosofia de JEAN-PAul SARTre
}

\author{
Thana Mara de Souza ${ }^{1}$
}

\begin{abstract}
RESUMO: Este artigo pretende mostrar como, a partir da noção de "vizinhança comunicante" estabelecida por Franklin Leopoldo e Silva, poderemos compreender os principais temas da filosofia sartriana e a relação entre eles, tais como a relação entre metafísica e história, sujeito e objeto, (liberdade) absoluta e concreta, e ética e estética. Ao estender a expressão inicialmente cunhada para a relação entre filosofia e literatura em Sartre, pretendemos evidenciar que as noções de ambiguidade e tensão são fundamentais para termos uma chave de leitura para todo o pensamento de Sartre.
\end{abstract}

PALAVRAS-CHAVE: Sartre. Vizinhança Comunicante.Ambiguidade. Tensão.

No livro Ética e Literatura em Sartre, Franklin Leopoldo e Silva analisa, em sua introdução, a relação entre filosofia e literatura para Sartre, e a define por meio de uma expressão: viz̨inhança comunicante, a qual pretendemos estender aqui, não a limitando à relação entre filosofia e literatura, mas a ampliando de sorte a nos permitir uma melhor compreensão da relação entre inúmeros outros termos que se relacionam do mesmo modo, na filosofia sartriana, tais como, dentre outros, metafísica e história, ontologia e fenomenologia, absoluto e concreto, sujeito e objeto, ser do fenômeno e fenômeno de ser, estética e ética. Nesse sentido, descreveremos a maneira como esses termos se relacionam e indicaremos uma "chave" de leitura para toda a obra de Jean-Paul Sartre, o que nos possibilitará também mostrar que, se existe ("ainda") uma metafísica sartriana, essa metafísica só faz sentido, nessa filosofia, como uma metafísica histórica, como uma metafísica que há muito se distanciou totalmente de seu sentido moderno.

\footnotetext{
1 Professora Doutora Adjunta I do Departamento de Filosofia da UFES (Universidade Federal do Espírito Santo). Pós-doutora pela Universidade de São Paulo. E-mail: thana.souza@gmail.com.
} 
Assim, partiremos da relação entre filosofia e literatura tão bem sublinhada por Franklin Leopoldo e Silva, ampliando-a a ponto de colocar a vizinhança comunicante como a descrição de quase todos os principais elementos da filosofia sartriana, o que nos levará às noções de ambiguidade e tensão como sendo chaves de leitura para compreender não só o pensamento de Sartre como também o que é a realidade humana para ele.

E, ao mostrar como essa expressão de vizinhança comunicante nos serve para entender todo o pensamento de Sartre, colocaremos também em questão mesmo que como pano de fundo - duas outras problemáticas inter-relacionadas que surgem ao longo da leitura crítica e que ao menos indicaremos não serem corretas: a da ruptura no pensamento de Sartre e a da identificação do pensamento de Sartre à modernidade.

A filosofia de Sartre foi interpretada de maneira bastante simplista, por parte dos filósofos e críticos contemporâneos a ele, que quase sempre enxergaram uma ruptura entre suas obras, que ora apontava para um idealismo total (abstrato, metafísico, burguês), ora para um realismo total (antropologia, psicologia, história), sendo estes lados antagônicos e, portanto, inconciliáveis. ${ }^{2}$

Porém, o que propomos tratar aqui é justamente de uma não-ruptura (não deixando, obviamente, de admitir mudanças de ênfases e perspectivas), é demonstrar como Sartre se coloca como projeto não a escolha pelo idealismo ou pelo realismo, mas pela tensão entre eles, não saindo do projeto moderno e, ao mesmo tempo, compreendendo-o de uma forma contemporânea.

Se é certo que é necessário "ainda" partir da noção de sujeito, o que situa Sartre bem longe de parte dos projetos contemporâneos (de Heidegger, Gadamer e Merleau-Ponty, por exemplo), é certo também que é necessário começar pela noção de sujeito para sair do sujeito (deixando Sartre bem longe do projeto moderno, no qual o sujeito não só era o ponto de partida, mas também o ponto de permanência). E é esse projeto que foi tão mal compreendido por boa parte da crítica. Para citar apenas um dos comentadores, podemos nos referir a Gerd Bornheim, que afirma explicitamente que Sartre era metafísico e depois se tornou histórico, ${ }^{3}$ como se se tratasse de termos totalmente separados, como se devêssemos entender metafísica no sentido moderno e história igualmente no

\footnotetext{
2 Para uma análise mais detalhada do modo como a crítica leu a filosofia de Sartre, cf. BELO, R. O paradoxo da liberdade: psicanálise e história em Sartre. Dissertação de mestrado defendida em 2006, no Departamento de Filosofia da Universidade de São Paulo.

${ }^{3}$ Como podemos ver, por esta citação: "A transformação que se verifica em Sartre resume-se no fato de que seu pensamento passa do plano meta-histórico ao histórico, e aquele parece subordinar-se agora a este" (BORNHEIM, 1971, p. 230).
} 
sentido moderno, ou seja, como excludentes. Contudo, o que Sartre propõe é a manutenção desses termos modernos compreendidos de uma forma nem um pouco moderna: se ainda há "metafísica" na filosofia sartriana, esse termo implica necessariamente pensar a "história", pensar a concretude e particularidade da realidade humana. E foi isso que boa parte dos críticos não percebeu: ao utilizar as mesmas palavras da filosofia moderna (ser, ontologia, metafísica, absoluto, sujeito, objeto), Sartre as empregava, no entanto, de um modo muito distinto de como a filosofia moderna o fez.

Com base nisso, pretendemos mostrar aqui, como pano de fundo, que não há uma ruptura na filosofia sartriana, que o pensar em termos metafísicos, absolutos e depois mais enfaticamente em termos históricos e concretos não significa que houve o abandono de uma teoria em prol de outra, mas que, no próprio termo "metafísico", de O ser e o nada, já havia a história, e no próprio termo absoluto já tínhamos, desde o começo, a necessidade de pensar o absoluto dentro do concreto.

Entretanto, não abordaremos diretamente a questão da ruptura ou unidade da filosofia de Sartre, nem o pertencimento ou não dessa filosofia à modernidade. Embora elas sejam nosso pano de fundo, o que está em questão neste artigo é evidenciar que, por meio das noções de ambiguidade e tensão, é possível encontrar uma chave para apreender corretamente os principais pontos da filosofia de Sartre (e será justamente essa chave que, nas entrelinhas, apontará o não haver ruptura alguma, ao longo dessa filosofia).

Comecemos, portanto, por verificar o que significa viz̧inhança comunicante, para Franklin Leopoldo e Silva.

Em seu livro Ética e literatura em Sartre, Franklin aponta, logo na introdução, a forma pela qual vê a relação entre filosofia e literatura, mais especificamente, uma filosofia fenomenológica e a literatura. Seguindo o que tanto Merleau-Ponty quanto Simone de Beauvoir ressaltam, em artigos da década de 1940, ${ }^{4}$ o que vemos no livro acima é o cuidado de estabelecer uma relação que não seja de subordinação ou de exemplo.

Quando se pensa em uma filosofia fenomenológica, ao nos lembrarmos da grande importância que não apenas Sartre como também Beauvoir, Merleau-Ponty e

\footnotetext{
${ }^{4}$ Cf. BEAUVOIR, S. Littérature et Métaphysique. Les Temps Modernes, avril 1946. Cf. Ainda MerleauPonty. Le roman et la métaphysique. Sens et non sens. cinquième edition. Paris: Nagel, 1966. Nesses artigos, tanto Simone de Beauvoir quanto Merleau-Ponty enfatizam que, no momento em que o sentido de metafísica se transforma com a fenomenologia, a relação da filosofia com a literatura também se modifica, deixando de se colocar em termos de hierarquia, para se colocar em termos de interdependência.
} 
Heidegger davam para a obra de arte, impossível reduzir toda e qualquer obra de arte a mero exemplo simplificador da filosofia, erro esse que infelizmente Paulo Perdigão ${ }^{5}$ comete, ao sustentar, no início de seu livro Existência e Liberdade, que as obras literárias e de teatro eram modos que Sartre encontrava de divulgar sua filosofia, de torná-la acessível a um público que não entenderia a linguagem filosófica.

O que Franklin Leopoldo e Silva salienta, porém, é que a relação entre a filosofia fenomenológica e a literatura é muito mais profunda e intrínseca do que a mera relação de exemplificação e simplificação. Roquentin (personagem do livro $A$ náusea) não é um exemplo, uma simplificação de como o homem tem náusea diante da contingência da vida, mas é a descrição, por meio do universal concreto, de como se dá a relação entre um determinado homem e seu mundo - e uma descrição que se dá através de uma linguagem muito específica, de uma linguagem que de modo algum se confunde com a linguagem filosófica e que consegue ser e mostrar a ambiguidade da condição humana a cada momento, a cada palavra dita, a cada silêncio.

Não se trata em nenhum momento de identificar literatura com filosofia (projeto de Derrida, por exemplo) - o tempo todo Sartre ressalta as diferenças no uso da linguagem (embora a ambiguidade também seja constitutiva da filosofia fenomenológica, é uma ambiguidade que se pretende menos ambígua, que não é procurada pelo filósofo a cada instante, como é o caso do escritor de romances) ${ }^{6}$; mas também não se trata em nenhum momento de estabelecer uma diferença absoluta entre filosofia e literatura, de sorte que uma poderia acontecer sem a outra, que uma não teria relação alguma com a outra, tal como a tradição filosófica parece achar.

O que vemos nessa relação entre filosofia e literatura é uma vizinhança comunicante, que significa assumir que não há uma relação externa nem uma identificação entre elas. A passagem de uma para a outra é uma passagem interna, de necessidade, de um complemento, mas nunca um complemento aleatório, externo: uma necessita da outra para alcançar seu objetivo próprio.

A princípio, não se trata de uma relação extrínseca e suspeitamos que não seja tampouco uma relação de identidade absoluta. A relação de uma com a outra se daria por uma espécie de comunicação que, à falta de outro termo, chamaríamos de passagem interna, querendo significar com isso que a vizinhança

\footnotetext{
${ }^{5}$ Excelente tradutor e autor de uma boa obra de introdução ao pensamento de Sartre.

${ }^{6}$ Em várias entrevistas publicadas em Situations IX, Sartre acentua o quanto a ambiguidade é constitutiva de toda linguagem, principalmente da linguagem que pretende tratar do homem (caso da filosofia e da literatura). Não se trata mais, portanto, de pensar na filosofia como uma ciência de rigor, mas também não é o caso de pensar a ambiguidade presente na filosofia como sendo igual à ambiguidade presente na literatura. Nessas entrevistas, o que podemos perceber é que a ambiguidade literária é justamente buscada e trabalhada pelo escritor, enquanto o filósofo é aquele que procuraria fazer suas ideias compreensíveis do modo mais claro possível, evitando, portanto, uma ambiguidade mais forte.
} 
entre filosofia e literatura é tal que não se precisaria, nem se poderia, sair de uma para entrar na outra, configurando assim dois espaços contíguos mas apenas indiretamente comunicáveis, ou seja, em que a passagem de um a outro se daria pela mediação da exterioridade. Pelo contrário, haveria uma forma de passar de um a outro que seria uma via interna, sem que, nesse caso, a comunicação direta anulasse a diferença. (SILVA, 2004, p. 13).

Essa separação entre filosofia e literatura acarreta uma comunicação interna entre elas, e não uma comunicação que fosse contingente e/ou externa, mas, por outro lado, essa comunicação interna e forte não anula, de maneira alguma, a separação entre esses dois modos de expressão.

Em Sartre, a metafísica não mais se identifica com intelecções abstratas sobre a possibilidade da realidade humana, nem com mundos eternos e abstratos, mas sim com a descrição da vivência humana, e, se é assim, essa filosofia precisa de uma forma de expressão que dê conta dessa vivência tal como ela é - ou seja, se a filosofia, embora longe do rigor matemático, lógico e analítico da modernidade, ainda se pretende uma estrutura, é necessário uma outra linguagem que realmente descreva compreensivamente o modo pelo qual cada homem vive sua condição e essa é a linguagem literária.

A expressão filosófica e a expressão literária são ambas necessárias em Sartre porque, por meio delas, o autor diz e não diz as mesmas coisas [...] Ora, se a literatura não serve apenas para ilustrar teorias filosóficas e se, no entanto, há uma identidade profunda entre as duas instâncias de expressão, segue-se, pensamos, que a diferença entre a elucidação da ordem humana e a descrição compreensiva de como os homens a vivem é ao mesmo tempo a identidade entre o nível das estruturas descritas fenomenologicamente e o nível das vivências narradas historicamente. (SILVA, 2004, p. 12-13).

Há uma diferença e uma identificação, ao mesmo tempo. Escrever filosofia não é escrever romance, e vice-versa; ${ }^{7}$ mas, se elas são diferentes, se a elucidação da ordem humana não é a descrição compreensiva das vivências, não se pode pensar uma sem a outra. A elucidação das estruturas (que são descritas de modo fenomenológico, por meio da filosofia) exige a narração dessas vivências de maneira histórica; e vice-versa.

O retrato feito pela narrativa precisa ser colocado em termos de elucidação, de reflexão - e esse movimento quem realiza é a fenomenologia, a qual, porém,

\footnotetext{
${ }^{7}$ Isso também pode ser visto em ensaios e entrevistas em Situations IX, nos quais Sartre admite ter escrito filosofia de modo mais fácil que romances. Para isso, cf. SOUZA, T. Sartre e a literatura engajada. São Paulo: EDUSP, 2008.
} 
no momento em que elucida, torna o retrato morto. E por isso é que essa relação não é unívoca, mas recíproca: a fenomenologia precisa que alguém faça um vivo retrato da realidade humana, diante seus dramas e angústias. ${ }^{8}$

Não é nossa pretensão analisar a exaustão essa relação, ${ }^{9}$ todavia, apenas mostrar o modo pelo qual Franklin Leopoldo e Silva a enxerga: na forma de uma vizinhança comunicante, em uma comunicação que se dá por passagem, que é necessária e interna. E, com base em uma análise do que significa esse termo, passaremos a explicar como, a partir dele, poderemos compreender com maior precisão e correção os mais fundamentais temas da filosofia sartriana.

E o que podemos explorar, nessa noção de viz̨inhança comunicante?

Em primeiro lugar, que se trata de uma vizinhança; portanto, de dois termos que não se misturam. Falar em uma vizinhança é pressupor casas ou apartamentos separados, é pressupor que há uma divisão, uma distinção entre uma residência e outra. Não são, portanto, termos que se desconstroem e se tornam indistintos, que se identificam. Há uma não confusão entre um termo e outro; no caso, entre literatura e filosofia.

No entanto (e é o que a segunda palavra da expressão indica), alude-se a uma vizinhança comunicante, ou seja, de uma vizinhança que não se isola, que tem um certo horizonte em comum; consiste em um termo que não se dá de modo independente do outro, de uma residência que, para ser residência, precisa da residência ao lado. Trata-se, portanto, de uma relação que mantém a distinção mas, ao mesmo tempo, exige uma comunicação, e uma comunicação que não é de forma alguma aleatória, contingente: é uma comunicação necessária e interna.

Ao utilizar essa expressão de vizinhança comunicante, Franklin Leopoldo e Silva nos deixa entrever não apenas a riqueza e profundidade da relação entre filosofia e literatura, mas o modo pelo qual os principais termos se relacionam, no pensamento sartriano. Para qualquer assunto que nos voltemos, dentro dessa filosofia, iremos nos deparar com uma relação entre termos aparentemente opostos, porém, que são unidos sem serem, no entanto, unificados. É o caso, como veremos depois, de desvelar a tensão e a ambiguidade dessa relação de

\footnotetext{
${ }^{8}$ Não se trata, nem nesse caso, nem em alguns que mostraremos ao longo do artigo, de estabelecer uma relação de interdependência que se dê do mesmo modo de um termo a outro; mas de enfatizar que ao menos há a necessidade de cada um deles se ligar ao outro. Quer dizer: a necessidade que a filosofia tem da literatura não se dá exatamente nos mesmos termos que a necessidade que a literatura tem da filosofia; mas, mesmo que não haja essa total identidade na forma da necessidade, uma necessariamente se comunica com a outra. Estabelecer, no entanto, em cada relação, esses diferentes modos de necessidade é trabalho para uma talvez futura obra.

${ }_{9}$ Para isso, cf. nota anterior.
} 
vizinhança comunicante, e é isso que nos possibilitará estabelecer uma chave de leitura de toda a obra filosófica de Sartre.

Continuando a explorar a noção proposta por Franklin Leopoldo e Silva, procuraremos agora expandir essa relação de vizinhança comunicante para outros termos essenciais, tais como: metafísica/história, absoluto/concreto, ontologia/ fenomenologia, ética/estética, ser do fenômeno/fenômeno de ser, sujeito e objeto.

Ao tentar compreender qualquer uma dessa lista de dicotomias acima citadas (que não se pretende exaustiva, mas apenas enumerativa), em todas elas poderemos perceber uma certa uniformidade na maneira de pensá-las - e que é, resumidamente, o modo da vizinhança comunicante.

Todas as questões do pensamento sartriano, ao serem aprofundadas, levarão a essa questão essencial que é já anunciada por Sartre (1999, p. 40, grifo nosso), na introdução de $O$ ser e o nada: "Se o idealismo e o realismo fracassam na explicação das relações que unem de fato essas regiões incomunicáveis de direito, que solução podemos dar ao problema?".

Como lidar com termos que são separados por direito e juntos, de fato?

A essa grande questão, sejam quais foram esses termos, a resposta sartriana será a mesma: pensar as duas situações ao mesmo tempo, o que é de direito e o que é de fato, pensar a comunicação necessária de fato sem, no entanto, tornar os termos inseparáveis de direito. Em outras palavras, é manter ao mesmo tempo as duas afirmações: a separação de direito e a união de fato. Em outras palavras, ainda, é optar, sempre, não por um dos termos, mas por ambos ao mesmo tempo - é optar pela tensão entre esses dois aparentes opostos. O que temos, em qualquer termo que escolhermos examinar com mais profundidade, dentro da filosofia sartriana, é a manutenção das duas afirmações acima: os termos sempre serão separados de direito, e sempre serão inseparáveis de fato.

A vizinhança comunicante entre literatura e filosofia, assim como entre as noções de metafísica e história, sujeito e objeto, ser do fenômeno e fenômeno de ser (entre outros termos), indica que os termos tensão e ambiguidade são justamente uma chave de leitura essencial para a compreensão da filosofia de Sartre, em sua totalidade, já que não encontramos, em nenhum momento, uma escolha total por um desses aspectos - a separação ou a junção; o idealismo ou o realismo - mas a manutenção constante e instável, por perspectivas distintas - de fato ou de direito - de ambos.

Assim, de certa forma, Sartre se mantém numa posição que ainda parece lembrar o projeto filosófico da modernidade. Há a manutenção dos termos 
metafísica, absoluto, ser, sujeito, filosofia como sistema - e, em nenhum momento, esses termos devem ser diluídos, mesclados, a ponto de deixarem de existir, aos termos história, concreto, existência, objeto, literatura.

Não temos aqui um "projeto contemporâneo", ao menos não no sentido que parte da filosofia contemporânea tentou conferir a esse projeto: o de tornar indistintos os dois termos, o empenho de não partir, de modo algum, do "sujeito" diante do "objeto", da "literatura" frente a "filosofia", em uma tentativa de desconstruir os termos, de ao menos não pensar mais a partir das noções colocadas pela modernidade. E não é isso que encontramos, na filosofia de Sartre.

Em decorrência, Bornheim não erra totalmente ao chamar Sartre de metafísico, já que é um termo que à primeira vista, "modernamente", o filósofo mantém. No entanto, erra ao interpretar esse metafísico em Sartre do mesmo modo como a tradição filosófica o compreendia.

A metafísica ${ }^{10}$, para nosso filósofo francês, não tem mais nenhuma relação com uma metafísica tradicional, no sentido de uma filosofia de sobrevoo, abstrata e alheia ao mundo concreto, que procura essências a-históricas, atemporais, que permaneceriam como fundamentais, mais importantes que a existência na história temporal. Se ainda há metafísica, é uma metafísica que não pode ser pensada fora da história, que não pode ser sem a concretude das vivências. A metafísica, para Sartre,

[...] não seria um conjunto de preocupações marcado pela distância que se abre entre a existência humana e a Substância ou o ser enquanto ser, mas um mergulho profundo na própria existência, não com a finalidade de transcendêla, mas de superar a obscuridade e a opacidade com que ela a princípio nos aparece, para que possamos então encontrar o absoluto, o universal e o transcendente nas imbricações concretas que fazem do homem uma questão para si mesmo. (SILVA, 2000, p. 59).

É, portanto, nas condições históricas que o homem é metafísico e absoluto. O homem é absoluto na sua hora e no seu meio. "É dentro dos limites humanos que o homem é absoluto, porque o mundo humano é algo de sua invenção e de sua responsabilidade. E sendo o mundo humano o lugar absoluto do homem, o absoluto é histórico" (SILVA, 2004, p. 30). ${ }^{11}$

\footnotetext{
${ }^{10}$ Para começar com uma das dicotomias mantidas, mas pensadas de fato como não dicotômicas.

${ }^{11}$ Cf. SARTRE, J.-P. Que é a literatura?: "Mas o que faz a originalidade da nossa posição, creio eu, é que a guerra e a ocupação, precipitando-nos num mundo em ebulição, forçaram-nos também a redescobrir o absoluto no interior da própria relatividade" (p. 159).
} 
Portanto, não estamos aludindo ainda a uma filosofia moderna. Se ainda são mantidos, os termos modernos o são para serem radicalmente transformados, obtendo um sentido que os afasta totalmente da filosofia tradicional. Se Sartre ainda parte dos termos considerados pertencentes à tradição filosófica, não é de modo algum para manter uma filosofia tradicional, mas para significar esses termos de maneira totalmente distinta de como a tradição o fazia, para, de um lado, não identificar um com o outro (sujeito com objeto, metafísica com história, absoluto com concreto, filosofia com literatura etc.), e, de outro, a não poder pensar um termo sem o outro - fazendo, dessas duas afirmações, dessa vizinhança comunicante, não uma contradição, mas uma ambiguidade, uma tensão - que será, afinal, o que é de mais originário na nossa condição humana.

Essa manutenção de dois termos separados de direito e ao mesmo tempo inseparáveis de fato, essa vizinhança comunicante necessária entre os dois termos, pode ser verificada, como já começamos a mostrar, em inúmeras noções sartrianas: metafísica/história, ontologia/fenomenologia, filosofia fenomenológica/literatura, ética/estética, ser do fenômeno/fenômeno de ser, Para-si/Em-si, (liberdade) absoluta/concreta.

Em todos esses termos, essenciais na filosofia de Sartre, podemos perceber uma dicotomia que permanece, porém, uma dicotomia que de fato não pode ser pensada por meio de termos separáveis e separados. Se a metafísica não é igual à história, se elas são termos distintos, que não se confundem (e, por isso, "ainda" a necessidade de manter uma metafísica, ao menos como horizonte nunca realizado, nem mesmo realizável em sua plenitude), de modo algum podemos atingir a metafísica sem ser na história, e não como maneira negativa, limitadora, mas como expressão positiva e esclarecedora da metafísica, já que esta, se não é exatamente a história, está na história.

Não pretendemos dar conta de todos os termos assinalados acima. Enfatizar como essa relação de vizinhança comunicante se dá em cada item da filosofia sartriana seria um projeto impossível de ser realizado em apenas um artigo. Escolheremos apenas umas poucas questões fundamentais dessa filosofia (em questões mais ontológicas) para mostrar como essa relação de vizinhança comunicante, ou o assumir a ambiguidade da separação de direito e junção de fato, nos permite melhor compreendê-las.

Entretanto, ao analisar com mais cuidado esses poucos aspectos, o que pretendemos é ressaltar que toda a filosofia de Sartre, para ser bem entendida, precisa partir desse pressuposto de assumir a dicotomia entre os termos, a qual exige, por seu turno, uma relação intrínseca e necessária entre os termos, sem optar por apenas um deles, nem mesmo pela indissociação entre eles, mas que 
sempre mantém a separação de direito (não há identificação, nem diluição de um termo no outro) e ao mesmo tempo uma junção de fato entre os termos (não se pode pensá-los de forma separada).

Comecemos pela análise da relação entre ser do fenômeno e fenômeno de ser, presente na introdução de $O$ ser e o nada. Para isso, no entanto, faremos uma breve exposição do projeto de Sartre, nessa parte do livro, apenas a fim de melhor assimilar como a questão do ser do fenômeno e do fenômeno de ser aparece.

Continuando o programa de Husserl, de estabelecer a consciência não mais como espaço, como substância, mas sim como um movimento em direção ao mundo, ${ }^{12} \mathrm{o}$ filósofo francês tenta radicalizar o esvaziamento da consciência e, ao fazer isso, reconhece igualmente a necessidade de a consciência ser sempre fora de si, em um certo mundo. Essa noção de intencionalidade da consciência aparece na introdução de $O$ ser e o nada, na tentativa de ir além do idealismo e do realismo. Porém, não estaríamos aqui "ainda" diante de um projeto filosófico da modernidade, que parte de um sujeito-consciência diante de um objeto-coisa? E como pensar assim poderia levá-lo a alcançar seu projeto de ir além do idealismo e do realismo ao mesmo tempo?

Se é certo que, como afirma Sartre em O ser e o nada, ${ }^{13}$ trata-se de partir da subjetividade, é certo também que é necessário partir da subjetividade não para se manter nela, para sair dela - e é exatamente o que ele fará, ao partir de um sujeito que de modo algum é solipsista, racional, inteiro; mas que é compreendido como sendo no mundo, como sendo justamente falta de ser, e uma falta que necessariamente se relaciona, de antemão, com o mundo e os outros homens. ${ }^{14}$ Isto é: é ao pensar o sujeito como consciência intencional que Sartre pretende se colocar além do idealismo e do realismo. Vejamos como.

Em primeiro lugar, porque essa noção implica colocar a consciência em relação ao mundo. Se a consciência passa a ser apenas um movimento em direção àquilo que ela não é, ou seja, ao mundo, então não há como pensar a consciência sem ao mesmo tempo pensar o mundo. A consciência não é senão nesse movimento de existência, nesse direcionar-se ao mundo. Dessa forma, Sartre pretende ter saído do idealismo, já que concebe o mundo como dado ao mesmo tempo em que a consciência: não é a consciência que cria o mundo, mas é a consciência que, para ser consciência, precisa de um mundo já dado.

\footnotetext{
${ }^{12}$ Como veremos mais à frente.

13 Cf. Capítulo 1 da Segunda Parte de O ser e o nada

${ }^{14}$ Para isso, basta aprofundar a noção de intencionalidade da consciência, já considerada desde as primeiras obras de Sartre.
} 
A constituição do mundo não é fundamentada pela consciência, e a consciência não pode ser pensada sem ser nessa relação com o mundo. Assim, se partirmos da noção de intencionalidade da consciência, torna-se impossível pensá-la isoladamente, sem estar numa relação necessária com o mundo.

Por outro lado, o mundo também não pode ser atingido a não ser por uma consciência. Se a existência do mundo não depende dessa consciência que o olhe, o sentido do mundo como "mundo", os significados que esse mundo tem são possíveis apenas porque uma consciência, que é, em seu ser, nada de ser, os posiciona, os intenciona. Não há como pensar o mundo como "mundo" sem colocá-lo numa relação necessária com a consciência. E é desse modo que a noção de intencionalidade vai além do realismo.

Temos, aqui, mesmo que exposto de maneira um tanto esquemática, a fuga do idealismo e ao mesmo tempo do realismo - e, nessa fuga, podemos começar a perceber a tensão também entre esses dois termos: consciência e mundo não se identificam de modo algum, mas um não pode ser pensado sem o outro. Como todos os termos que indicamos, até este ponto, trata-se de manter a separação de direito entre consciência e mundo, e de manter, ao mesmo tempo, a impossibilidade de separá-los de fato. Trata-se de estabelecer uma relação de vizinhança comunicante (um não sendo o outro e um tendo uma comunicação necessária e intrínseca com o outro) - enfim, de manter e assumir a tensão da manutenção da separação de direito e, ao mesmo tempo, da inseparabilidade de fato.

Todavia, se é assim, se o mundo só é mundo por meio de uma consciência que o posiciona, que coloca uma tese dele, não seríamos levados ao idealismo, no dizer que o mundo é só aquilo que a consciência dele percebe?

Como já começamos a demonstrar, não é isso que ocorre na filosofia de Sartre. E isso porque a própria noção de intencionalidade acarreta, por um lado, que o mundo seja dado de antemão e não construído pela própria consciência. Mas, como pensar o fenômeno, para que seja possível não cair no idealismo?

Para evitar que o "ser seja ser percebido" (frase de Berkeley a que Sartre recorre, para ilustrar o idealismo), Sartre necessita sublinhar que o fenômeno tem uma existência independente da consciência. Se o sentido desse fenômeno só é dado pela consciência, isso não significa, para nosso filósofo, que o fenômeno dependa da consciência. Como, em Que é a literatura?, o autor enfatiza: "Essa paisagem, se dela nos desviarmos, se estagnará, longe dos olhos, em sua permanência obscura. Pelo menos ela só se estagnará: não há ninguém suficientemente louco para acreditar que ela desaparecerá” (SARTRE, 2004, p. 34). 
A questão, portanto, é mostrar a dependência do fenômeno enquanto "fenômeno", enquanto com certo sentido e significado, e a independência do fenômeno enquanto existente (e diante do qual a consciência existe). Mas, para que o fenômeno não tenha sua existência dependente da consciência, Sartre o dotará de um ser transfenomenal - isto é: o fenômeno não é apenas sua manifestação limitada e imediata, mas contém, em sua manifestação, um ser.

Há, por conseguinte, um "ser do fenômeno" que não se restringe ao "fenômeno de ser", que não está inteiramente na manifestação. Contudo, afirmar que há esse "ser do fenômeno" não seria retornar a Kant, não seria distinguir radicalmente o fenômeno da coisa em si e fazer desta o incognoscível?

Novamente, não. Sartre tenta manter-se o tempo todo num instável equilíbrio e, se há o "ser do fenômeno", esse ser não se encontra oculto, alheio ao fenômeno. Pelo contrário: nessa filosofia, o ser do fenômeno não se identificará com o fenômeno de ser, mas estará no fenômeno de ser. "O ser dos fenômenos não se soluciona em um fenômeno de ser, e contudo, não podemos dizer nada sobre o ser salvo consultando este fenômeno de ser" (SARTRE, 1999, p. 20).

Não é o caso de identificar o ser do fenômeno com o fenômeno de ser, nem de colocar esse ser como algo oculto, totalmente alheio ao próprio fenômeno (duas formas distintas de cair no idealismo, na primeira relativizando a existência do fenômeno à percepção que temos dele; e a segunda,postulando uma Ideia, uma coisa em-si que seria atemporal, independente de nossa existência). O que Sartre estabelece é uma relação de vizinhança comunicante entre esses dois elementos: o ser do fenômeno não é o fenômeno de ser, mas tem uma passagem interna e necessária ao fenômeno de ser. Falar do ser do fenômeno é falar do fenômeno de ser, e este não será apenas um elemento negativo do ser do fenômeno, no entanto, será positivamente o ser, porque

[...] em resumo, o fenômeno de ser é "ontológico" [...]. É um apelo ao ser; exige, enquanto fenômeno, um fundamento que seja transfenomenal. $\mathrm{O}$ fenômeno de ser exige a transfenomenalidade do ser. Não significa que o ser se encontre escondido atrás do fenômeno (vimos que o fenômeno não pode mascarar o ser), nem que o fenômeno seja uma aparência que remeta a um ser distinto (o fenômeno é enquanto aparência, quer dizer, indica a si mesmo sobre o fundamento do ser). As precedentes considerações presumem que o ser do fenômeno, embora coextensivo ao fenômeno, deve escapar à condição fenomênica - na qual alguma coisa só existe enquanto se revela - e que, em conseqüência, ultrapassa e fundamenta o conhecimento que dele se tem. (SARTRE, 1999, p. 20). 
Há uma dupla implicação, uma relação de necessidade intrínseca entre um elemento e outro: o fenômeno de ser exige a transfenomenalidade do ser, assim como o ser não pode ser apreendido senão por meio do próprio fenômeno. Esse ser exigido pela manifestação não é um ser da filosofia tradicional, mas um ser que é coextensivo ao próprio fenômeno, sem, não obstante, se identificar com este.

O que temos aqui é exatamente a mesma relação que Franklin Leopoldo e Silva estabelece, a respeito da literatura e da filosofia: uma vizinhança comunicante entre termos que são vizinhos e, portanto, separados, mas que ao mesmo tempo se indicam, precisam um do outro para cada um existir. Se o fenômeno exige a transfenomenalidade de seu ser, o ser, por sua vez, é coextensivo ao fenômeno. Ao ser do fenômeno não é possível ser em um alheamento, em uma nunca referência ao fenômeno. Embora ele escape dessa condição de ser enquanto se revela, embora seja a condição mesma desse desvelamento do fenômeno, não é senão enquanto fenômeno de ser. Enquanto o fenômeno de ser apela ao ser do fenômeno, este se volta para o próprio fenômeno, atendendo ao apelo, que o compromete, que faz com que também o ser se envolva nessa existência fenomenal (embora não se resuma a ela).

$\mathrm{Na}$ introdução de $\mathrm{O}$ ser e o nada, ao elaborar a proposta de ir além do realismo e do idealismo, Sartre mostra, em primeiro lugar, como a consciência e o mundo se relacionam como vizinhos que necessariamente se comunicam, numa comunicação interna, intrínseca e necessária, sem que haja, por isso, uma dissolução de um termo no outro - a separação de direito se mantém, mas não pode ser, de fato, pensada de forma a poder pensar um termo sem o outro.

Todavia, não bastasse essa ambiguidade de conservar Para-si e Em-si como separados de direito e inseparáveis de fato, Sartre duplica essa dicotomia em relação ao fenômeno: se é certo que o fenômeno, para existir independentemente da consciência, exige a transfenomenalidade como seu fundamento, é certo também que esse "ser do fenômeno" não se encontra em um outro mundo, oculto, mas se revela em cada fenômeno, que pode, pois, ser apreendido positivamente como manifestação do ser.

Não apenas a relação entre consciência e mundo, entre sujeito e objeto, é uma relação de vizinhança comunicante, na qual temos de conservar ao mesmo tempo a separação de direito e a inseparabilidade de fato, como também no próprio objeto temos essa nova dicotomia entre o fenômeno de ser e o ser do fenômeno: sem se identificarem, um exige o outro e não pode ser pensado sem que o outro surja.

O fenômeno exige o ser, e o ser não se dá fora do fenômeno. Em decorrência, podemos compreender por que Sartre, ao aludir a uma metafísica, 
a uma ontologia, está necessariamente falando de história e fenomenologia, já que, do mesmo modo como o ser do fenômeno se mostra no fenômeno de ser, a metafísica se dá na história e a ontologia se faz por meio da fenomenologia. ${ }^{15}$ Essa é a razão de Sartre (1999, p. 19) argumentar: "O ser nos será revelado por algum meio de acesso imediato, o tédio, a náusea etc.; e a ontologia será a descrição do fenômeno de ser tal como se manifesta, quer dizer, sem intermediário".

O ser é revelado em sua existência, em seu acesso imediato; a ontologia é a descrição do fenômeno tal como ele aparece, enquanto a metafísica só pode ser acessada por meio da história. Não temos, em nenhum desses casos (ser do fenômeno/fenômeno de ser, ontologia/fenomenologia, metafísica/história), uma anulação da dicotomia, a tentativa de embaralhar os termos. Pelo contrário: de direito, esses termos são separados e necessariamente separados. No entanto, essa dicotomia é exposta por Sartre de uma maneira sui generis: não se trata mais de pensar uma dicotomia infinito/finito, mas a dicotomia do "infinito no finito". É a isso que Sartre se refere, na introdução de $O$ ser e o nada, quando salienta que todas as dicotomias da filosofia moderna foram agora reduzidas a uma nova dicotomia: à dicotomia do infinito no finito, numa relação entre termos que não se identificam, mas não são mais totalmente separáveis, de fato.

Temos, portanto, essa relação do infinito no finito no caso da relação entre esses termos de "ser do fenômeno" e "fenômeno de ser", metafísica e história, ontologia e fenomenologia. Se a relação ainda fosse a do infinito/finito sem que houvesse uma relação entre eles, ainda continuaríamos a ver o fenômeno de ser, a história e a vivência como meramente negativos. Contudo, não é disso que se trata: Sartre enfatiza que não devemos colocá-los como dois termos meramente separados, que nessa separação há ao mesmo tempo uma junção, que o infinito se dá no finito, embora não se resuma a ele. Ou seja, positivamente, o ser do fenômeno é acessado pelo fenômeno de ser, assim como a metafísica se dá positivamente na história, como a ontologia se dá, positivamente, por meio das descrições imediatas da realidade humana, em sua máxima concretude.

A relação que podemos perceber, pela análise do ser do fenômeno e do fenômeno de ser, é a de uma vizinhança comunicante, a qual indica assim a manutenção da ambiguidade, ao afirmar ao mesmo tempo a separação de direito e a inseparabilidade de fato. A tensão dessa comunicação necessária e intrínseca se mantém o tempo todo, e é por meio desse equilíbrio instável que Sartre pretende construir sua filosofia.

${ }^{15}$ Não pretendemos aqui esgotar a questão, mas apenas indicar que a relação é a mesma. 
Como escreve em outro momento de $O$ ser e o nada ${ }^{16}$, optar por uma das visões opostas, por apenas um desses termos, seria "[...] escapar de Caribdes e cair em Cila" (SARTRE, 1999, p. 150). Essa imagem pode ser aplicada às relações acima analisadas: não é nunca ficar apenas de um só lado, não é nunca ficar apenas no idealismo abstrato de uma metafísica, ontologia, absoluto, ser do fenômeno; assim como também não é nunca ficar apenas no realismo relativista de uma história, fenomenologia, concretude, fenômeno de ser. É admitir os dois lados ao mesmo tempo; é, como destaca Sartre sobre a noção de liberdade, considerar os dois lados de uma mesma moeda (o ser absoluta e concreta ao mesmo tempo).

Tanto na relação do ser do fenômeno com o fenômeno de ser, tanto na relação da metafísica com a história, do absoluto com o concreto, da ontologia com a fenomenologia, da filosofia com a literatura, temos uma só moeda, mas uma só moeda que é composta por dois lados distintos. E é isso que Sartre enfatiza o tempo todo, e é isso que os críticos e comentadores compreenderam tão mal: o ser do fenômeno está no fenômeno de ser, embora eles não se tornem indistintos; a metafísica está na história, apesar de não se identificar com ela; a ontologia está na fenomenologia, ainda que não seja a mesma coisa. Concretamente, de fato, essa díade forma uma só estrutura, mas uma estrutura que é feita por dois elementos de direito distintos.

Fenômeno de ser não é ser do fenômeno, mas apela a ele, indica-o, como um lado da moeda indica seu outro lado. O ser do fenômeno não é o fenômeno de ser, porém, está no fenômeno, não pode ser pensado como se estivesse oculto, alheio à manifestação. Do mesmo modo que o fenômeno de ser clama por um ser do fenômeno, este, para ser, precisa apelar para um fenômeno de ser, já que só existe na manifestação, na concretude.

$\mathrm{E}$ é isso que se repete, nos outros termos apenas citados por nós: metafísica/história, ontologia/fenomenologia, (liberdade) absoluta/concreta. Sempre a manutenção de uma dicotomia, mas de uma dicotomia que se distingue - e muito - de como é pensada pela tradição filosófica: trata-se, em Sartre, de uma dicotomia que implica ao mesmo tempo uma relação necessária e intrínseca entre os dois termos, de sorte que, de fato, não se possa pensar um sem ao mesmo tempo pensar o outro.

É, como temos repetido à exaustão (mas uma exaustão que se justifica, porque a pretensão deste artigo é justamente mostrar uma chave que permita melhor compreender os temas mais fundamentais da filosofia de Sartre), a relação de vizinhança comunicante, uma relação que aponta, por um lado, para a

\footnotetext{
${ }^{16}$ Ao esclarecer sua concepção do Para-si como ser dos possíveis, referindo-se a Aristóteles e a Leibniz.
} 
necessidade de separar de direito os elementos; e por outro, para a necessidade de ao mesmo tempo juntá-los de fato.

A descrição da expressão viz̧inhança comunicante como modo de Sartre relacionar os termos de sua filosofia revela noções que serão fundamentais como ponto de partida e permanência, para que possamos entender de maneira mais profunda sua filosofia: as noções de ambiguidade e tensão. Por meio da descrição da relação de todos os termos supracitados (fenômeno de ser/ser do fenômeno, literatura/filosofia, sujeito/objeto, metafísica/história, ontologia/fenomenologia, ética/estética etc.), podemos deduzir que há certa uniformidade na forma como Sartre lida com sua filosofia, que é, por fim, o mesmo modo pelo qual o filósofo pensa a realidade humana: por meio da ambiguidade e da tensão.

Compreender o que é vizinhança comunicante é perceber que a tensão está presente em toda a filosofia de Sartre, é observar que em nenhum momento a ambiguidade é desfeita, nem a tensão eliminada. Trata-se de partir da condição humana como ambiguidade e mantê-la por meio de uma tensão que reúne a separação de direito dos elementos e sua inseparabilidade de fato. Sartre não apenas parte da ambiguidade como o que há de mais originário na realidade humana, mas também estabelece que o modo pelo qual o homem se assume como homem é justamente por meio da assunção dessa ambiguidade, por meio da reflexão sobre o fracasso da tentativa de eliminar nossa tensão.

O que torna o homem autêntico, como veremos um pouco deste ponto em diante, é o assumir o fracasso da tentativa necessária e vã de eliminar nossa ambiguidade fundamental (que é a de ser Para-si, e portanto, a de ser o ser que busca o si, que busca a síntese do Para-si-Em-si, busca necessária mas impossível de ser realizada, justamente porque somos Para-si, porque nossa estrutura é sermos presença a si ${ }^{17}$ e fazer desse fracasso a assunção de nossa realidade como ambiguidade e, ao assumir essa tensão, fazermo-nos homens, ou seja, o ser que, por ser falta de ser, desvela o mundo por meio de seu fazer.

Em Cadernos para uma moral ${ }^{8}$, Sartre considera a autenticidade como uma conversão e não como uma superação, o que já nos indica que não podemos pensá-la como a forma pelo qual sairíamos de todas as ambiguidades e nos colocaríamos acima delas, ou integrando-as numa síntese na qual haveria total harmonia.

\footnotetext{
17 Cf. SARTRE, J.-P. O ser e o nada (primeiro capítulo da segunda parte).

${ }^{18}$ Cf. SOUZA, T. Em busca da autenticidade prometida: uma leitura de Cadernos para uma moral. In: CARNEIRO, M. C.; GENTIL, H. S. (Org.). Filosofia Francesa Contemporânea. São Paulo: Cultura Acadêmica, 2009.
} 
Não se trata de ignorar a tensão, de ignorar que, em primeiro lugar, o homem é Para-si que deseja ser Em-si-Para-si, mas se trata de, diante do desejo necessário e vão da busca da completude nunca alcançável, assumir o fracasso de sair da tensão e fazer dele a possibilidade mesma de ser humano.

Expliquemos melhor.

Vemos, em $O$ ser e o nada, que o homem é sempre busca da completude, da totalidade, da síntese denominada Em-si-Para-si (que uniria a translucidez da consciência à determinação e a opacidade do Em-si), todavia, se essa busca é necessária, se não há como deixar de sê-la, é verdade também que ela será sempre frustrada: ao Para-si, justamente porque sua estrutura mais imediata é ser Presença-a-si (não coincidência com o mundo nem consigo mesmo), sempre persistirá uma distância, um desgarramento em relação ao mundo, aos outros, ao que ele foi e ao que ele será. É impossível alcançar a total identidade consigo mesmo e é impossível deixar de ser essa busca, pois somos justamente esse movimento em direção ao que não somos. Mas se é assim, como pensar uma possibilidade de autenticidade, de não tentar se refugiar em uma certa identidade, coincidência, completude, essência?

A isso, Sartre responde, em Cadernos para uma moral, que não se trata de deixar de buscar a síntese impossível. Não haveria como deixar de ser o desejo do si que nos falta, o desejo daquilo que nunca alcançaremos. No entanto, se isso é verdade, se uma superação desse desejo de ser não é possível, é verdade igualmente que esse desejo pode ser convertido, ou seja, pode ser significado pelo homem de uma maneira diferente.

É a isso que Sartre chama de "conversão". O homem autêntico será aquele que, buscando ainda a síntese impossível, a translucidez e a opacidade ao mesmo tempo, saberá que essa busca é tão necessária quanto impossível de ser alcançada. E, ao tomar consciência desse fracasso, não tentará ignorá-la nem eliminá-la por meio da má-fé, mas irá assumi-lo e até mesmo desejá-lo, já que ele se vê, no fracasso dessa busca, como sendo aquele que não é Deus, ou seja, como sendo aquele que é homem. Assim, o assumir o fracasso da tentativa de eliminar a ambiguidade da busca necessária e vã, esse homem se compreende como aquele para quem sempre faltará o si, e por isso mesmo, como aquele para quem o mundo existe com certo sentido, certo significado. $O$ fracasso do desejo humano é, ao mesmo tempo, a possibilidade mesma de nos fazermos humanos.

A "salvação" não estaria nem na "paixão de Cristo" (que ignoraria o fracasso, e faria dele apenas um meio para alcançar a Vitória), nem na "paixão do poeta" (que assumiria o fracasso de tal forma a fazer da vida uma total impossibilidade), mas na "paixão do convertido" (aquele que reconheceria o 
fracasso da solução da tensão e, ao assumi-lo, faz-se humano). Ou, em outras palavras, o homem autêntico não seria nem aquele que vive no "paraíso" nem aquele que vive no "inferno", mas aquele que vive no "purgatório" - enfim, aquele que aceita a ambiguidade de ser humano, aquele que aceita a tensão entre a necessidade do desejo e a impossibilidade de satisfazer totalmente esse desejo e, ao aceitá-las, faz-se como aquele para quem a vida é justamente o fazer (e não o ser).

O homem autêntico é, na filosofia de Sartre, portanto, aquele que assume de modo positivo a angústia de sermos ambiguidade, aquele que, ao invés de tentar separar os termos de fato ou tentar torná-los inseparáveis de direito, assume a tensão da relação de vizinhança comunicante, assume ao mesmo tempo a separação de direito e a inseparabilidade de fato. Aceitando a necessidade dessa busca pelo Em-si-Para-si e ao mesmo tempo desejando o fracasso dessa busca, esse homem autêntico faz do fracasso a assunção de sua condição mais fundamental e, ao assumi-lo, assume a dignidade de ser homem.

Assim, a compreensão da relação entre os principais termos da filosofia sartriana como uma relação de vizinhança comunicante nos levou às noções de ambiguidade e tensão como chaves tanto para entender todo o pensamento de Sartre, quanto para compreender o que é a realidade humana para ele. Não apenas os termos relatados ao longo do artigo (filosofia/literatura, metafísica/história, ontologia/fenomenologia, ser do fenômeno/fenômeno de ser, absoluto/ concreto, sujeito/objeto) devem ser descritos em termos de uma vizinhança comunicante, como também revelam que nossa realidade humana é, no que tem de mais profundo e humano, ambígua. E é ao assumir essa tensão que o homem se faz homem, com toda sua angústia e com toda sua dignidade.

A ampliação da expressão viz̨inhança comunicante, tão bem empregada pelo filósofo Franklin Leopoldo e Silva, ao tratar da relação entre filosofia e literatura, levou-nos a interpretar melhor a estrutura do pensamento de Sartre como manutenção de uma dicotomia, mas uma dicotomia que afasta o filósofo francês do projeto filosófico da modernidade, quer dizer, uma dicotomia que necessita da afirmação da separação de direito entre os termos e ao mesmo tempo da afirmação da inseparabilidade de fato entre eles. Em outras palavras, a compreensão da vizinhança comunicante nos indica a escolha pela manutenção da ambiguidade e pela assunção da tensão como as principais chaves de leitura para toda a obra de Sartre, mesmo porque essas noções enfatizam não apenas a relação entre o que é de direito e de fato (a aspiração pelo universal e a impossibilidade de sair totalmente do concreto), mas porque nos revelam também (e principalmente) a condição humana, no que ela tem de mais verdadeiro. 
Agradecimentos: ao Prof. Franklin Leopoldo e Silva.

SOUZA, Thana Mara de. Tension and ambiguity in the philosophy of Jean-Paul Sartre. Trans/Form/Ação, Marília, v. 35, n. 1, p. 147-166, Jan./Abril, 2012.

\begin{abstract}
This article intends to show how, on the basis of the notion of "communicating neighborhood" established by Franklin Leopoldo e Silva, we may understand the main themes of Sartre's philosophy and the relations between them, e.g., the relations between metaphysics and history, subject and object, absolute and concrete (freedom), and aesthetic and ethics. By extending an expression initially established for the relation between philosophy and literature in Sartre, we intend to show that the notions of ambiguity and tension are essential as a key to all of Sartre's thought.
\end{abstract}

KEYWORDS: Sartre; communicating neighborhood ;ambiguity; tension.

\title{
REFERÊNCIAS
}

BEAUVOIR, S. Littérature et métaphysique. Revue Les Temps Modernes. Paris, avril/1946.

BELO, R. Oparadoxo da liberdade: psicologia e história em Sartre. 2006. Dissertação (Mestrado em Filosofia) - Faculdade de Filosofia, Letras e Ciências Humanas da Universidade de São Paulo, São Paulo, 2006.

BORNHEIM, G. Sartre: metafísica e existencialismo. São Paulo: Perspectiva, 1971.

MERLEAU-PONTY, M. Le Roman et la métaphysique. Sens et non sens. 5. ed. Paris: Nagel, 1966.

PERDIGÃO, P. Existência e liberdade: uma introdução à filosofia de Sartre. Porto Alegre: L\&PM, 1995.

SARTRE, J.-P. O ser e o nada. Petrópolis: Vozes, 1999.

- Que é a literatura? São Paulo: Ática, 2004.

. Situações I. São Paulo: Cosac \& Naify, 2006.

.Cabiers pour une morale. Paris: Gallimard, 1983.

- A náusea. Rio de Janeiro: Nova Fronteira, s/d.

. Situations IX. Paris: Gallimard, 1972. 
SILVA, F. Ética e literatura em Sartre. São Paulo: UNESP, 2004.

- Metafísica e História no romance de Sartre. Revista Cult, maio 2000.

SOUZA, T. Sartre e a literatura engajada: espelho crítico e consciência infeliz. São Paulo: EDUSP, 2008.

Em busca da autenticidade prometida: uma leitura de Cadernos para uma moral. In: CARNEIRO, M. C.; GENTIL, H. S. (Org.). Filosofia Francesa Contemporânea. São Paulo: Cultura Acadêmica, 2009.

Recebido em: 29.09.2011

Aprovado em: 01.12.2011 